\title{
Sistemi ortofrutticoli sostenibili
}

\author{
Albino Maggio, ${ }^{1}$ Raffaele Testolin, ${ }^{2}$ Giorgio Gianquinto ${ }^{3}$ \\ ${ }^{1}$ Dipartimento di Ingegneria Agraria e Agronomia del Territorio, Università di Napoli Federico II, \\ Portici; ${ }^{2}$ Dipartimento di Scienze Agrarie e Ambientali, Università di Udine; ${ }^{3}$ Dipartimento di \\ Scienze e Tecnologie Agro Ambientali, Università di Bologna, Italy
}

\begin{abstract}
The sustainability of agricultural production systems is a recurrent topic in the public debate, tightly linked to resource use efficiency and energy saving principles. Higher yield with lower input is the paradigm that will guide us in the years to come. This will unavoidably call for a joint effort of different players from research, production and policy sectors. In this scenario, research has a key role since it is the only instrument that may generate a continuous flux of information that in the short-, medium- and long-term could effectively contribute to defining innovative production systems, more efficient and with a reduced environmental impact. In this short review, some aspects of sustainability in horticultural systems will be presented with a particular focus on the implementation of proven technology, production in saline environments and breeding strategies to improve crops resource use efficiency.
\end{abstract}

Correspondence: Giorgio Gianquinto, Dipartimento di Scienze e Tecnologie Agro Ambientali, Università di Bologna, viale Fanin 44, 40127 Bologna, Italy. Tel. +39.051.2096240 Fax: +39.051.2096245.

E-mail: giorgio.gianquinto@unibo.it

Key words: urban agriculture, salinity, plant breeding.

Parola chiave: agricoltura urbana, salinità, miglioramento genetico.

Ringraziamenti: si ringrazia Stefania De Pascale per i commenti al manoscritto e gli utili suggerimenti. Albino Maggio ha curato l'organizzazione del lavoro e la sezione Sostenibilità delle produzioni in ambiente salino; Giorgio Gianquinto ha curato la sezione Implementazione di proven technology: agricoltura urbana sostenibile, Raffaele Testolin ha curato la sezione Creazione di varietà adatte ad una coltivazione sostenibile. La relazione è stata presentata da Giorgio Gianquinto al congresso AISSA 2010.

Received for publication: 16 March 2011.

Accepted for publication: 15 May 2011.

Società rappresentata nell'ambito AISSA: Società di Ortoflorofrutticoltura Italiana - SOI.

(C) Copyright A. Maggio et al., 2011

Under no circumstances figures can be used without prior written consent of the copyright owner.

Licensee PAGEPress, Italy

Italian Journal of Agronomy 2011; 6(s2):e3

doi:10.4081/ija.2011.6.s2.e3

This work is licensed under a Creative Commons Attribution NonCommercial 3.0 License (CC BY-NC 3.0).

\section{Riassunto}

La sostenibilità dei sistemi produttivi agricoli è argomento di grande attualità, legato, in principio, all'uso più efficiente delle risorse disponibili e ad un minor dispendio energetico. Higher yield with lower input è il paradigma che ci guiderà negli anni a venire e richiederà inevitabilmente uno sforzo congiunto dei diversi attori del settore della ricerca, della produzione e legislativo. In questo scenario, la ricerca gioca un ruolo fondamentale perché unica in grado di generare un flusso continuo di informazioni che nel breve, medio e lungo periodo possano contribuire alla definizione di nuovi sistemi produttivi, più efficienti e con ridotto impatto ambientale. In questa breve review verranno presentati alcuni aspetti della sostenibilità dei sistemi ortofrutticoli con riferimento all'implementazione di proven technology, alla coltivazioni in ambienti estremi e al miglioramento genetico per ottimizzare l'uso delle risorse disponibili.

\section{Introduzione}

L'uso sostenibile delle risorse in funzione della salvaguardia ambientale e dell'incremento della popolazione mondiale è al centro dell'attenzione internazionale. Su questa linea la Commissione Europea ha definito, con la comunicazione Europa 2020, ${ }^{1}$ il programma strategico per una crescita smart, sustainable e inclusive. Il documento individua le linee guida per raggiungere un futuro sostenibile attraverso il coordinamento di programmi europei e nazionali e indica cinque obiettivi quantificabili che dovranno essere raggiunti entro il 2020: i) il 75\% della popolazione tra i 20-64 anni deve avere un lavoro; ii) il 3\% del PIL deve essere investito in Ricerca e Sviluppo; iii) l'obiettivo $20 / 20 / 20^{2}$ relativo a clima ed energia deve essere raggiunto; iv) la percentuale di abbandono nei primi anni di scuola dovrà essere inferiore al 10\% ed almeno il 40\% dei giovani dovrà aver completato con successo le scuole superiori; v) 20 milioni di persone in meno dovranno essere a rischio di povertà. Anche se mai esplicitamente scritto nell'intero programma, l'agricoltura ha un ruolo determinante per il raggiungimento di questi obiettivi ed è pertanto un elemento essenziale del nostro futuro sostenibile. La sensibilità scientifica, sociale e politica verso le problematiche ambientali è cresciuta significativamente nell'ultimo ventennio, come documentato dall'incremento esponenziale del numero di pubblicazioni associate in vario modo al concetto di sostenibilità (Figura 1).

${ }^{1}$ http://ec.europa.eweu2020/index_en.htm

${ }^{2}$ http://ec.europa.ewenvironment/climat/climate_action.htm 
A queste si aggiungono numerose analisi, forward looks, foresights e position papers (ESF, 2009; European Commission, 2009; The Royal Society, 2009) che attraverso un approccio interdisciplinare hanno cercato di guardare al sistema agro-alimentare nel suo insieme e nelle sue molteplici sfaccettature di carattere ambientale, economico e socio-culturale. Se dall'analisi della letteratura emerge una difficoltà oggettiva nell'individuazione di modelli generali che definiscano percorsi ideali per raggiungere la sostenibilità, dall'altro bisogna constatare che spesso in queste analisi la descrizione di scenari attuali e futuri non è sempre seguita da concrete opzioni strategiche per il loro raggiungimento, così come non è sempre chiaro quali siano i costi associati a determinate scelte.

Benché ci possa essere una posizione condivisa sulla necessità di produrre più efficientemente e nella salvaguardia ambientale, esistono dei forti elementi di contrasto che vanno considerati. L'opposizione al taglio delle foreste, sink importante per il controllo dei livelli di $\mathrm{CO}_{2}$ atmosferica, si contrappone a un'auspicata crescita economica dei paesi in via di sviluppo che, dalla messa a coltura di nuove aree per la coltivazione, ad esempio, di palme da olio ${ }^{3}$ (Bayon e Jenkins, 2001), possono beneficiare di un miglioramento delle economie locali; ed ancora, se da un lato l'agricoltura biologica e la produzione di biocarburanti sono spesso presentati come due esempi di attività sostenibili dal punto di vista agro-ambientale ed energetico (OECD, 2007), dall'altro queste attività sono allo stato attuale in apparente contrasto con la necessità di soddisfare i fabbisogni alimentari della popolazione mondiale che nel 2050 potrebbe superare i 9 miliardi.

I trend registrati negli ultimi anni indicano che la domanda di alimenti crescerà più rapidamente dell'offerta in seguito allo sviluppo di economie emergenti e alla conseguente richiesta di una più ampia varietà di alimenti. Aumentare la quantità di cibo disponibile è pertanto ancora obiettivo primario per il prossimo ventennio (Federoff et al., 2010; FAOSTAT ${ }^{4}$ ). Molti vedono in una nuova rivoluzione verde l'unica possibilità di incrementare la produzione di cereali del $50 \%$, quanto previsto sia necessario per soddisfare le esigenze in proteine animali (carne e prodotti caseari) della popolazione mondiale (Cassman, 1999; Alexandratos, 1999). Questi cambiamenti determineranno inevitabilmente un nuovo assetto dei sistemi agricoli, tuttavia lo scenario attuale è sostanzialmente differente da quello degli anni ' 60 in cui la rivoluzione verde ha, di fatto, triplicato le rese.

${ }^{3}$ http://www.cifor.cgiar.org/Headlines/palm-oil-a-path-prosperity-poor-indonesians.htm ${ }^{4}$ http://faostat.fao.org/

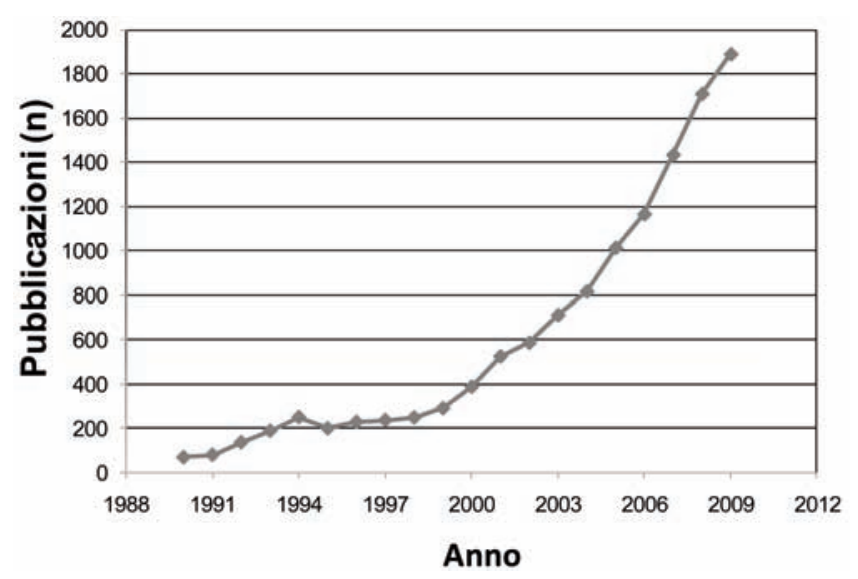

Figura 1. Numero di pubblicazioni in PubMed che includono il termine sustainable nel titolo, abstract o keywords nel periodo 1990-2009.

Figure 1. Number of PubMed publications including the word sustainable in the title, abstract or keywords in 1990-2009.
Gli agricoltori oggi devono operare con risorse idriche limitate, incrementi di temperatura e condizioni climatiche instabili, minimi incrementi marginali di produzione in seguito all'applicazione di fertilizzanti, competizione per usi no-food dei terreni, riduzioni delle rese dovute a patologie e danni da insetti che allo stato attuale incidono per circa il $40 \%$ sulle rese potenziali, aumenti nel prezzo dei carburanti e assenza di tecnologie innovative per aumentare la produzione (Tilman et al., 2001).

La combinazione di questi fattori pone una forte pressione sul sistema agricolo in generale ed evidenzia la necessità di individuare nuove strategie per aumentare l'efficienza dei sistemi agricoli e ridurre le perdite post-raccolta. La ricerca e l'innovazione tecnologica avranno un ruolo essenziale in questo processo sia rispetto ai risultati raggiungibili nei varie settori scientifici che all'implementazione di questi negli specifici contesti colturali. Di seguito saranno illustrati, in tre aree delle produzioni ortofrutticole, tre possibili percorsi per migliorare la sostenibilità dei processi produttivi in presenza di risorse limitate.

\section{Implementazione di proven technology: agricol- tura urbana sostenibile}

Da sempre, il termine agricoltura è strettamente associato all'ambiente rurale e per il sentire comune è un'attività produttiva confinata a tale contesto. Partendo da questo presupposto, per lungo tempo si è pensato che per fornire cibo alla crescente popolazione urbana - nel maggio del 2007 la popolazione mondiale residente nelle aree urbane ha superato quella rurale e le proiezioni indicano che entro il 2020 il $55 \%$ della popolazione del pianeta vivrà nelle città e che tale percentuale salirà al 60\% e 70\% nel 2030 e 2050, rispettivamente (UN-DESA, 2007) - potesse essere sufficiente la produzione fornita dalle campagne 0 al massimo dalle aree peri-urbane.

Per molte città del Sud del Mondo, tuttavia, tale congettura si è rivelata del tutto inesatta, principalmente a causa della carenza di infrastrutture efficienti (trasporti, mercati, ecc.) e per la mancanza di potere d'acquisto da parte della popolazione più povera (Drescher, 2004). L'aumento della povertà e la mancanza di lavoro, oltre alle opportunità che la città può offrire, come la crescente domanda di beni alimentari e la vicinanza dei mercati, hanno stimolato una diversificazione dei sistemi di produzione agricola, dentro 0 nelle periferie delle città, specializzati principalmente nella produzione di prodotti deperibili come ortaggi, latte fresco e uova (Gianquinto e Tei, 2010). Tali sistemi di agricoltura urbana - orientati sia all'autoconsumo e alla sussistenza, sia al mercato - sono complementari alle produzioni provenienti dalle campagne e aumentano l'efficienza globale del sistema alimentare (Veenhuizen, 2006). Si stima che circa 200 milioni di agricoltori urbani riforniscano i mercati delle città, contribuendo per il $15-20 \%$ alla produzione di cibo nel Mondo (Armar-Klemesu, 2000).

Nonostante alcune attività siano transitorie, l'agricoltura urbana è di fatto diventata caratteristica permanente in molte città, sia dei paesi in via di sviluppo sia in quelli già sviluppati, tanto da attirare l'attenzione dei governi che da alcuni anni hanno intrapreso azioni per promuoverla (Holmer et al., 2003; Veenhuizen, 2006) e delle Nazioni Unite che hanno individuato nell'agricoltura urbana una delle strategie più importanti per raggiungere gli Obiettivi del Millennio, Millennium Development Goals (Mougeot, 2005).

In ambiente urbano il settore dell'orto-frutticoltura è indubbiamente quello di maggior rilievo e, in linea generale, mentre all'interno delle città si preferisce coltivare ortaggi a ciclo breve e a elevato reddito (Tabella 1), le zone peri-urbane sono riservate alle orticole a ciclo più lungo 0 ai frutteti (Gianquinto e Tei, 2010). La coltivazione nelle aree urbane e peri-urbane differisce in modo sostanziale rispetto a quella in ambiente rurale. Le città, soprattutto nei Paesi in Via di Sviluppo, stan- 
no crescendo rapidamente, con crescenti esigenze di suolo edificabile e conseguente aumento dei prezzi dei terreni. In tali contesti, l'accesso alla terra per i produttori urbani è piuttosto difficile e rappresenta il limite maggiore per la loro attività (Tixier e Bon, 2006). Di conseguenza, i produttori spesso occupano abusivamente terreni marginali con problemi di fertilità che, oltre a limitare la produttività, restringono notevolmente la scelta delle specie da coltivare. L'incertezza riguardo all'occupazione del suolo porta a sfruttare al massimo il terreno, anche tramite l'uso massiccio di fertilizzanti chimici e fitofarmaci, per avere risultati nell'immediato senza alcuna considerazione per gli effetti di medio e lungo termine. Inoltre, le città sono nella maggior parte dei casi molto inquinate e la grande sfida degli orticoltori urbani e quella di far crescere e produrre le piante in condizioni di forti stress, determinate spesso da elevate concentrazioni di $\mathrm{SO}_{2}, \mathrm{NO}_{2}$ e ozono nell'aria dovute al traffico veicolare molto intenso (Agrawal et al., 2003) e alla contaminazione del suolo e dell'acqua di irrigazione con metalli pesanti, idrocarburi, residui di agrofarmaci e microrganismi patogeni (Buechler et al., 2006; Cofie et al., 2006).

Si ha poi l'effetto isola di calore che si riscontra in tutte le città, ma che risulta particolarmente critico negli ambienti tropicali, in cui è spesso difficile far crescere le piante, anche molte meso- e macroterme, durante i periodi più caldi (Gianquinto e Tei, 2010). Durante le stagioni delle piogge, a causa dell'impermeabilizzazione dei suoli nelle aree urbane, si verificano spesso allagamenti e l'erosione del terreno è molto intensa. L'intensità delle precipitazioni in questi ambienti è tale che spesso non è possibile la coltivazione negli orti di piena aria. In tali condizioni la coltivazione risulta molto difficile e limita molto la scelta delle specie.

Per far fronte a queste problematiche, sono state sviluppate nuove tecnologie per ottimizzare la coltivazione in spazi ridotti, anche in terreni di scarsa fertilità e qualità, per aumentare l'efficienza dell'acqua irrigua, per ridurre l'uso di agrofarmaci e per minimizzare l'impatto dell'attività orticola su salute umana e ambiente. Alcuni sistemi utilizzano in larga misura substrati naturali e compost di vario tipo (es. organoponica), altri fanno riferimento a tecniche di coltivazione fuori suolo semplificate. Queste tecnologie trovano applicazione in luoghi diversi e trovano frequentemente posto sui tetti degli edifici (Deesohu Saydee e Ujereh, 2003; Shariful Islam, 2004), contribuendo anche a migliorare le condizioni termiche delle abitazioni (Eumorphopoulos e Aravantinos, 1998) e a ridurre il consumo di energia per il raffrescamento (Wong et al., 2003).

\section{Sistemi organoponici}

I sistemi organoponici prevedono la coltivazione su substrati organici là dove sono presenti terreni con fertilità molto bassa e per supplire alla mancanza di input chimici. Le colture sono generalmente effettuate dentro buche o solchi o contenitori fuori terra, riempiti con compost 0 materiale organico di diversa provenienza (qualità e sanità). L'impiego di sterco animale propriamente compostato permette di ottenere produzioni elevate e prodotti salubri. È una tecnica diffusa particolarmente in Venezuela e a Cuba (Cruz e Medina, 2003; Tixier e Bon, 2006). A Cuba, questo sistema di orticoltura urbana è promosso e fortemente sostenuto da programmi governativi dalla fine degli anni ' 80 , quando la caduta del blocco sovietico e l'inasprimento delle sanzioni USA hanno causato seri problemi d'insufficienza alimentare (Altieri et al., 1999). I sistemi organoponici cubani prevedono l'impiego di un substrato di coltivazione rappresentato da una miscela composta da $50 \%$ di terreno e $50 \%$ di sostanza organica (spesso rappresentata da sottoprodotti dell'industria saccarifera) e forniscono prodotti per il consumo familiare o per le mense delle scuole, degli ospedali e dei luoghi di lavoro; gli orti organoponici vengono condotti da privati o cooperative (Novo e Murphy, 2000). A L'Havana ne sono presenti più di 450, di cui circa una ventina sono considerati ad alta produttività, in grado di fornire una media di $16 \mathrm{~kg}$ di ortaggi per $\mathrm{m}^{2}$ (Murphy, 1999). Si coltivano una ventina di ortaggi ma la specie più coltivata è la lattuga (circa il 50\% della produzione) seguita da spinacio, basilico, cipolle, cardi, ecc. (Murphy, 1999). Queste tecnologie di produzione sono strettamente legate a pratiche agronomiche eco-sostenibili, in particolare al miglioramento della fertilità per mezzo di microorganismi ed ai sistemi integrati e biologici per il controllo delle malattie (Prain, 2006). Cuba è leader mondiale nella produzione ed uso di entomopatogeni, che vengono prodotti in centri specializzati e distribuiti attraverso una moltitudine di canali, tra cui corner shop e centri di assistenza tecnica (Rosset e Benjamin, 1994).

\section{Sistemi idroponici semplificati}

I sistemi idroponici semplificati sono fortemente raccomandati dalla FAO e sono attualmente presenti in molti Paesi di Africa, Asia e America Latina. Con questo termine sono indicati sia i sistemi idroponici veri e propri, in cui le radici sono immerse direttamente nella soluzione nutritiva (es. floating system), sia quelli che prevedono la coltivazione su substrati di varia natura, alimentati con soluzioni nutritive. I secondi non presentano limiti d'impiego nelle differenti condizioni climatiche ed ambientali, mentre i primi difficilmente possono essere utilizzati in ambienti troppo caldi (per la bassa concentrazione di ossigeno nella soluzione nutritiva - inversamente proporzionale alla temperatura - e la conseguente scarsa ossigenazione degli apparati radicali) 0 in cui vi è presenza di malattie trasmesse da zanzare (es. malaria) che possono deporre le uova nelle vasche di coltivazione (Gianquinto e Tei, 2010).

Tabella 1. Reddito generato da diversi sistemi agricoli nell'area di Kumasi, Ghana (modificato da Danso et al., 2002).

Table 1. Revenue generated by different farming systems in Kumasi, Ghana (Danso et al., 2002, modified).

\begin{tabular}{|c|c|c|c|c|c|}
\hline \multirow{2}{*}{$\begin{array}{l}\text { Area di ubicarione } \\
\text { delle attività }\end{array}$} & \multirow[t]{2}{*}{ Sistema agricolo } & \multirow{2}{*}{$\begin{array}{l}\text { Periodo di } \\
\text { coltivazione }\end{array}$} & \multirow{2}{*}{$\begin{array}{l}\text { Dimensione } \\
\text { araiendale } \\
\text { (ha) }\end{array}$} & \multicolumn{2}{|c|}{ Reddito netto (US\$) } \\
\hline & & & & $\begin{array}{l}\text { US\$ ha-1 } \\
\text { anno-1 }\end{array}$ & $\begin{array}{c}\text { US\$ azienda }{ }^{-1} \\
\text { anno }^{-1}\end{array}$ \\
\hline $\begin{array}{l}\text { Rurale o } \\
\text { peri-urbana }\end{array}$ & Mais o mais/cassava (no irrigazione) & Tutto l'anno & $0,5-0,9$ & $350-550$ & $200-450$ \\
\hline Peri-urbana & Orticoltura (irrigazione) & Stagione secca & $0,4-0,6$ & $300-350$ & $140-170$ \\
\hline Peri-urbana & $\begin{array}{l}\text { Orticoltura (irrigazione) } \\
\text { Mais e orticoltura } \\
\text { (no irrigazione) }\end{array}$ & $\begin{array}{l}\text { Stagione secca } \\
\text { Stagione umida }\end{array}$ & $0,7-1,3$ & $500-700$ & $300-500$ \\
\hline Urbana & $\begin{array}{l}\text { Orticoltura (ortaggi da foglia, cavolo, cipolla) } \\
\text { (irrigazione) } \\
\text { Orticoltura (ortaggi da foglia, cavolo, cipolla) } \\
\text { (no irrigazione) }\end{array}$ & $\begin{array}{l}\text { Stagione secca } \\
\text { Stagione umida }\end{array}$ & $0,1-0,2$ & $2000-8000$ & $400-800$ \\
\hline
\end{tabular}


La convenienza nell'adottare questi sistemi, evidenziata da diverse esperienze e studi (Marulanda e Izquierdo, 2003; Izquierdo, 2006; FAO, 2007; Gianquinto et al., 2007b; Rodríguez-Delfín, 2008; Orsini et al., 2010c), deriva da:

la possibilità di coltivare in spazi ridotti (es. cortili, patii, terrazze e tetti) e in condizioni di scarso accesso a suoli fertili;

a possibilità di intensificare i cicli colturali, con conseguenti aumenti di produzione, permessa sia dalla maggiore precocità di produzione rispetto alla coltivazione su suolo sia dalla possibilità di coltivare anche nei periodi in cui quest'ultima non è praticabile (es. stagioni delle piogge);

l'elevata produzione per unità di superficie determinata dalla maggiore densità colturale che viene adottata rispetto alle colture su suolo e dalla costanza nel rifornimento di acqua e nutrienti;

la minore incidenza delle malattie trasmesse dal terreno, tipiche delle coltivazioni tradizionali;

la migliore qualità delle produzioni che deriva dalla migliore nutrizione idrica e minerale e dal minore impiego di fitofarmaci;

la possibilità d'utilizzare materiali di scarto e/o sottoprodotti localmente reperibili a basso costo, da impiegare come substrati di coltivazione (es. lolla di riso, foglie di bamboo, fibra di cocco e cortecce di palma) o contenitori (es. bottiglie PET, pneumatici, taniche, latte e bidoni);

il ridotto sforzo fisico richiesto per la coltivazione che rende questi sistemi più facilmente accessibili a donne ed anziani.

L'adozione di sistemi a ciclo chiuso (con recupero e riutilizzo della soluzione nutritiva di drenaggio) permette, inoltre, di ridurre considerevolmente il consumo e le perdite di acqua e nutrienti, con diminuzione dei costi di produzione ed eliminazione dei rischi d'inquinamento del suolo e delle falde (Tixier e Bon, 2006; Gianquinto e Tei, 2010).

I sistemi idroponici semplificati più diffusi prevedono la costruzione di casse di legno di $1-2 \mathrm{~m}^{2}$, profonde $20-40 \mathrm{~cm}$, sollevate da terra (80$100 \mathrm{~cm}$ ), impermeabilizzate con film plastico e riempite con soluzione nutritiva (Rodríguez-Delfín et al., 2004; Orsini et al., 2010a). Le piante sono collocate su pannelli forati di polistirolo che galleggiano sul mezzo liquido (floating system) e lo ricoprono completamente, permettendo un efficace controllo dello sviluppo delle alghe. La soluzione nutritiva deve essere arieggiata frequentemente, 0 con interventi manuali o per mezzo di pompe. Questo sistema idroponico è caratterizzato da un elevato volume della soluzione nutritiva, da ridottissime perdite di acqua (l'evaporazione è minima) e dalla possibilità di utilizzare la soluzione nutritiva per più cicli colturali. In alternativa, le stesse casse possono essere riempite di substrato (es. lolla di riso, fibra di cocco) su cui si esegue la semina 0 il trapianto; le piante sono irrigate quotidianamente con soluzione nutritiva e quella in eccesso è raccolta tramite un foro di drenaggio per poi essere riutilizzata (Rodríguez-Delfín et al., 2004; Orsini et al., 2010b).

Un altro sistema modulare è costituito da una vasca d'irrigazione collocata a circa $2 \mathrm{~m}$ di altezza e da una vasca di drenaggio: la soluzione nutritiva fluisce dalla prima, scorre all'interno di file di bottiglie di plastica (questo sistema idroponico è denominato garrafas PET) 0 grondaie o canne di bamboo - riempite di substrato (es. lolla di riso, fibra di cocco) e in cui sono alloggiate le piante - assicurate ad una struttura in legno inclinata (pendenza del $20-25 \%$ ), per poi raggiungere la seconda vasca collocata a valle del sistema. Si tratta di un sistema a ciclo chiuso in cui la fertirrigazione è continua durante le ore di luce ed avviene attraverso un sistema di irrigazione a goccia che prevede dei gocciolatori collocati sulla prima bottiglia, o all'inizio di ogni fila. Una 0 due volte al giorno, in funzione della capacità delle vasche, la soluzione nutritiva di drenaggio viene riportata nella vasca di irrigazione ed eventualmente reintegrata con soluzione nutritiva fresca (Gianquinto et al., 2007a). Questo sistema può essere inserito all'interno di serre tropicali, coperte con reti ombreggianti per ridurre la radiazione solare.
Nei sistemi idroponici semplificati i punti critici riguardano la qualità dell'acqua e la disponibilità di fertilizzanti. Se si ha a disposizione acqua con elevata concentrazione salina o contaminata da agenti chimici e/o biologici la sua gestione può risultare problematica. L'ideale è avere la possibilità di raccogliere le acque piovane che sono caratterizzate da bassa conducibilità elettrica, ridotta carica microbica e di alghe. Nella formulazione della soluzione nutritiva bisogna cercare di ottenerne una che vada bene per il maggior numero di ortaggi, utilizzando i fertilizzanti idrosolubili disponibili in loco.

Orientativamente la concentrazione dei diversi nutrienti dovrebbe ricadere all'interno dei seguenti intervalli:

$\mathrm{N}$ totale $13-18 \mathrm{mM} \mathrm{l}^{-1}\left({\mathrm{~N}-\mathrm{NO}_{3}}_{3}\right.$ 2-15 $\left.\mathrm{mM} \mathrm{l}^{-1}\right), \mathrm{P}$ 1.4-3.0 $\mathrm{mM} \mathrm{l}^{-1}, \mathrm{~K}$ 6-11 $\mathrm{mM} \mathrm{l}^{-1}$, S 1.5-6.0 $\mathrm{mM} \mathrm{l}^{-1}$, Ca 3.2-5.0 $\mathrm{mM} \mathrm{l}^{-1}, \mathrm{Mg}^{1.2-3.5} \mathrm{mM} \mathrm{l}^{-1}$, Fe 10-40 $\mu \mathrm{M} \mathrm{I}^{-1}, \mathrm{Cu}$ 0.5-1.0 $\mu \mathrm{M} \mathrm{I}^{-1}$, Zn 4-7 $\mu \mathrm{M} \mathrm{I}^{-1}$, B 15-40 $\mu \mathrm{M} \mathrm{I}^{-1}$, Mn 10-15 $\mu \mathrm{M}$ $\mathrm{l}^{-1}$, Mo 0.5-0.8 $\mu \mathrm{M} \mathrm{I}^{-1}$.

A volte è necessario l'impiego di un numero elevato di concimi, che complica la gestione della soluzione nutritiva e deve essere eseguita da personale tecnico specializzato. Non sembra al momento praticabile l'impiego di acque reflue o l'impiego di concimi organici al posto della soluzione nutritiva preparata con fertilizzanti minerali, come auspicato da alcuni autori (Mavrogianopoulos et al., 2002).

\section{Sostenibilità delle produzioni in ambiente salino}

Secondo stime dell FA0 circa $1 / 5$ dei terreni irrigati è affetto da problemi di salinità (Rozema e Flowers, 2008). Questa situazione è ulteriormente aggravata dalla competizione per l'acqua destinata ad usi agricoli, domestici o industriali (UN, 2009). La salinizzazione dei suoli e delle acque d'irrigazione oltre ad essere responsabile della riduzione delle rese è causa dell'abbandono di alcune aree agricole e limita la messa a coltura di nuove.

In tale contesto, la sostenibilità delle produzioni agricole va quindi considerata rispetto ad almeno tre elementi di criticità: i) l'apporto inevitabile di sali associato alla pratica dell'irrigazione; ii) la riduzione delle risorse idriche disponibili e iii) i cambiamenti climatici - con particolare riferimento alla riduzione delle precipitazioni e agli aumenti di temperatura che possono aggravare i problemi da salinità in aree particolarmente sensibili.

L'irrigazione, necessaria per le colture ortive, comporta un accumulo di sali nella zona radicale che può non incidere significativamente sulle rese e la qualità dei prodotti se contenuto entro limiti di tolleranza (dipendenti fondamentalmente da caratteristiche genetiche e quindi dalla specie e cultivar). Tuttavia, anche per le colture più tolleranti la salinità raggiunge rapidamente la soglia critica quando un regime irriguo inadeguato e precipitazioni insufficienti non consentono di allontanare l'eccesso di sali al di sotto della zona radicale (Maggio et al., 2010). In base allo scenario attuale è evidente che esiste un problema di gestione nell'immediato, ma allo stesso tempo vi è l'esigenza di investire più risorse per comprendere a fondo le relazioni pianta-stress negli specifici sistemi colturali al fine di definire metodologie di coltivazione e programmi di miglioramento genetico adeguati.

La sostenibilità delle produzioni in ambiente salino dovrà quindi guardare a diversi aspetti: i) l'applicazione di principi agronomici generali per minimizzare i danni alle colture e controllare i livelli di salinizzazione/deterioramento dei suoli nel lungo periodo; ii) lo sviluppo di tecnologie innovative, cioè quelle all'interfaccia tra conoscenza scientifica acquisita e applicazione; iii) l'acquisizione di nuove conoscenze sulla fisiologia dello stress al fine di sviluppare nuove strategie per migliorare l'adattabilità delle colture ad ambienti sfavorevoli. A questi tre aspetti ci si riferirà nelle sezioni che seguono con sostenibilità nel breve-, medio- e lungo-periodo. 


\section{Sostenibilità nel breve periodo}

Le tecnologie disponibili per gestire le coltivazioni in ambiente salino sono descritte in numerosi testi, tra cui l'Irrigation and Drainage Paper 29 Rev.1 e l'Irrigation and Drainage Paper 48 della FA0 restano due manuali di riferimento (Ayers e Westcot, 1994; Rhoades et al., 1992). Poiché la salinizzazione dei suoli è strettamente legata alla pratica dell'irrigazione, il controllo della progressione del fenomeno inizia con una gestione efficiente di quest'ultima attraverso l'uso di metodologie consolidate (De Pascale et al., 2011) e l'ausilio di software specifici (ad es. CROPWAT ${ }^{5}$ ) per il calcolo dei fabbisogni idrici delle colture. Nel caso specifico dell'uso di acque saline, è necessario che un volume d'acqua in eccesso rispetto a quello richiesto per soddisfare l'evapotraspirazione (fabbisogno di lisciviazione) attraversi la zona radicale affinché non si verifichi in questa un accumulo di sali (Ayers e Westcot, 1994). Altre indicazioni specifiche che vanno considerate per rallentare il progredire della salinizzazione riguardano la scelta del metodo irriguo, i tipi di lavorazione, l'uso di ammendanti e concimi minerali/organici che possano migliorare gli aspetti chimico-strutturali $(\mathrm{pH}$, permeabilità, SAR) dei suoli deteriorati dall'eccesso di sali (Rhoades et al., 1992; Ayers e Westcot 1994). Tecniche per migliorare l'adattabilità delle colture all'ambiente salino includono il seed priming (Alvarado et al., 1987; Cano et al., 1991), seedling conditioning (Amzallag et al., 1990) e l'uso di micorrize (Hirrel e Gardemann, 1980; Copeman et al., 1996). Nei casi in cui i sistemi colturali lo consentano, vanno considerate strategie di riciclo di acque di drenaggio che mirano ad utilizzare risorse idriche con diversi livelli di salinità nella maniera più efficiente, massimizzando il loro uso in funzione di diversi livelli di tolleranza delle colture (Rhoades et al., 1992).

La scelta della specie più idonea in ambiente salino è un altro elemento importante da considerare. Soglie critiche di tolleranza, vale a dire livelli di conducibilità elettrica dell'estratto saturo (ECe) a cui iniziano a verificarsi riduzioni delle rese, sono state ottenute per la maggior parte delle specie di interesse agrario (Maas e Grattan, 1999). Pur con i limiti intrinseci di questo criterio di valutazione, determinati da fattori ambientali che possono alterare la risposta alla salinità (Dalton et al., 2000), la soglia di tolleranza per i principali ortaggi li classifica secondo quanto segue: pomodoro (Lycopersicon esculentum Mill.) $\mathrm{EC}_{\mathrm{e}}$ $2.5>$ cavolo cappuccio (Brassica oleracea var. capitata L.) $\mathrm{EC}_{\mathrm{e}} 1.8>$ patata (Solanum tuberosum L.) ECe $1.7>$ peperone (Capsicum annuum L.) $\mathrm{EC}_{\mathrm{e}} 1.5>$ cipolla (Allium cepa L.) ECe $1.2>$ melenzana (Solanum melongena $\mathrm{L}$.) $\mathrm{EC}_{\mathrm{e}} 1.1>$ fagiolo (Phaseolus vulgaris $\mathrm{L}$.) ECe 1.0 (Maas e Grattan, 1999). In alcuni casi e per alcune colture ortive (per le quali la qualità organolettica è il principale determinante del prezzo di mercato) si sono definiti equilibri specifici di sostenibilità come ad esempio per il pomodoro e il melone di Pachino, dove le minori rese dovute alla salinità dell'acqua di irrigazione sono compensate dall'elevato valore attribuito dal consumatore a queste produzioni. In altri casi, il recupero e l'utilizzo di ecotipi locali tolleranti a stress idrico/salino ha invece consentito la coltivazione in condizioni insostenibili per le varietà commerciali selezionate ed allo stesso tempo la reintegrazione di materiale ad elevata potenzialità nei programmi di miglioramento genetico (Cuartero e Munoz, 1999).

Per le colture ad elevato reddito, floricole ed ornamentali, l'uso di impianti di desalinizzazione ad osmosi inversa trova una specifica sostenibilità economica (De Pascale e Maggio, 2008).

\section{Sostenibilità nel medio periodo}

Come vedremo di seguito, lo sviluppo di nuovi strumenti di ricerca ha consentito nel corso degli ultimi anni di testare ipotesi in maniera molto più accurata e puntuale contribuendo alla comprensione di meccanismi fisiologici essenziali per l'adattamento (Pardo, 2010).

${ }^{5}$ http://www.fao.org/nr/water/infores_databases_cropwat.html
Ciò che invece ha ricevuto minore attenzione è la contestualizzazione delle risposte di tolleranza rispetto a specifici sistemi colturali, un'area che potrebbe facilitare il processo di technology transfer contando anche su una più efficiente/efficace collaborazione tra agronomi, crop physiologists e biologi molecolari (Maggio et al., 2011).

L'irrigazione ripetuta con acque saline, associata ad una riduzione delle precipitazioni, può comportare modifiche sostanziali e permanenti delle proprietà del suolo (Rhoades et al., 1992). I suoli salinizzati, dopo un intervento irriguo o una pioggia, spesso presentano un più elevato contenuto idrico a causa sia di una riduzione della traspirazione da parte delle colture che di una ridotta permeabilità conseguente alla formazione di croste superficiali dovuta alla deflocculazione delle argille (Hachicha et al., 2000; De Pascale et al., 2005). In questi casi le colture devono gestire non solo fenomeni associati allo stress salino per se ma anche all'asfissia radicale. L'analisi dell'evolversi dei fenomeni di stress nell'arco di una stagione colturale e di più cicli colturali (Maggio et al., 2005) è importante per individuare la combinazione più appropriata, per un dato ambiente colturale, di caratteri fisiologici da potenziare e tecniche agronomiche da implementare. In ambienti mediterranei ad esempio, dove stress idrico e salino spesso coesistono, le colture rispondono a stress giornalieri, conseguenti ad elevati VPD nelle ore più calde della giornata, e stagionali dovuti all'accumulo di sali nel corso dell'irrigazione primaverile-estiva (De Pascale et al., 2003). La sovrapposizione di più stress può attribuire, inoltre, un ruolo differente agli stessi meccanismi fisiologici rispetto allo stadio di sviluppo della pianta e alla stagione colturale (Maggio et al., 2004). Benché l'accumulo di soluti compatibili (responsabili per l'aggiustamento osmotico) e l'omeostasi ionica siano stati i target più immediati per potenziare la tolleranza allo stress tramite ingegneria genetica (Chinnusamy et al., 2005; Pardo, 2010), ad oggi non è ancora chiaro quale meccanismo di tolleranza sia funzionalmente più importante nei diversi stadi fenologici (Sakamoto e Murata, 2002). Dove la salinizzazione può avere un carattere stagionale (irrigazione estiva per le colture ortive), i livelli critici di salinità possono raggiungersi a ciclo colturale avanzato in coincidenza con l'allegagione o più in là nella fase di sviluppo delle bacche nel caso del pomodoro. In questo stadio fenologico, meccanismi di accumulo/traslocazione di ioni tossici nelle foglie più vecchie, documentato in diverse specie, potrebbero risultare più efficaci rispetto al potenziamento della compartimentalizzazione ionica vacuolare e/o della produzione di soluti compatibili (Pardossi et al., 1998; Maggio et al., 2005). In pomodoro, è stato dimostrato che l'accumulo di $\mathrm{Na}^{+}$nelle foglie più vecchie è funzionale all'adattamento allo stress salino (Amzallag, 2002; Zhu, 2002; Zhang e Blumwald, 2001; Maggio et al., 2007). La base fisiologica e genetica che consente un più efficiente accumulo di $\mathrm{Na}^{+}$e $\mathrm{Cl}^{-}$nelle foglie fotosinteticamente meno efficienti non è nota, per cui certamente questo non può propriamente ritenersi un carattere isolabile e/o trasferibile a medio termine. Ma è importante sottolineare quanto un'analisi più attenta di specifici contesti colturali possa evidenziare target sinora trascurati. In questa categoria rientrano molti altri caratteri morfologici mai testati in ambiente salino, come ad esempio la morfologia/architettura radicale. In carenza idrica, un maggiore sviluppo radicale consente di esplorare un più ampio volume di suolo e pertanto di superare meglio la disidratazione del suolo (Cuartero e Fernàndez-Muñoz, 1999; Nelson et al., 2007). Meno chiaro è invece il comportamento degli apparati radicali in presenza di stress salino: ampi apparati radicali rispetto a ridotti sviluppi fogliari potrebbero essere deleteri perché faciliterebbero l'accumulo di ioni tossici nelle foglie anticipando l'insorgenza della soglia critica di tossicità (Dalton et al., 2000). In linea con questa ipotesi è stato dimostrato in specie del genere Citrus che un ridotto rapporto radici-chioma aumenta la tolleranza allo stress salino (Moya et al., 1999). La disponibilità di numerosi mutanti radicali in Arabidopsis potrebbe essere uno strumento efficace per individuare morfologie radicali funzionali all'ambiente salino ed ottenere informazioni utili per il miglioramento genetico 
(Maggio et al., 2001; Yu et al., 2008; Morant et al., 2010).

Sempre nell'ambito dei caratteri morfologici, solo di recente è stata individuata nella densità stomatica una delle componenti fisiologiche fondamentali per il controllo della water use efficiency (WUE) (Masle et al., 2005; Yu et al., 2008). In assenza di stress, una ridotta densità stomatica aumenta la WUE (Thompson et al., 2007). Resta da confermare se anche in presenza di stress questo carattere possa facilitare l'adattamento e/o tolleranza.

Un ultimo esempio in relazione ad azioni a medio-termine che possano contribuire ad aumentare la sostenibilità dei sistemi produttivi in ambiente salino riguarda il controllo ormonale dell'adattamento allo stress (vedi anche sezioni successive). Fino ad oggi il controllo (endogeno o esogeno) dei livelli di acido abscissico (ABA) per migliorare l'adattabilità delle colture a situazioni di stress non ha dato risultati incoraggianti dal punto di vista applicativo. L'ABA somministrato per via fogliare 0 nella soluzione nutritiva può consentire di superare situazioni transitorie di stress in quanto, inducendo la chiusura stomatica, preserva lo stato di idratazione e quindi la turgidità dei tessuti fino al ristabilirsi di condizioni ottimali. Tuttavia la chiusura stomatica riduce anche i flussi di $\mathrm{CO}_{2}$ in ingresso con effetti a lungo termine negativi sulla crescita (Maggio et al., 2002b). In linea con queste osservazioni, mutanti di Arabidopsis con bassi livelli di ABA hanno mostrato un'ipersensibilità allo stress a elevato $\mathrm{VPD}$, mentre hanno manifestato tolleranza allo stress salino in condizioni di basso VPD (atmosfera satura) (Ruggiero et al., 2004). Se da un lato questi risultati hanno confermato l'insostenibilità dell'utilizzo di piante con livelli alterati di ABA in pieno campo, dall'altro hanno fornito informazioni importanti in relazione ad un possibile uso in ambiente controllato (serra) dove il controllo del VPD può mitigare gli effetti negativi di una ridotta chiusura stomatica in risposta a stress iperosmotico (De Pascale e Maggio, 2008).

\section{Sostenibilità nel lungo periodo}

Nell'ultimo ventennio il modello classico di studio della risposta allo stress, basato sull'esistenza di molecole che percepiscono e trasducono il segnale di stress per attivare geni funzionali all'adattamento (Maggio et al., 2004), si è sensibilmente evoluto arricchendosi di ulteriori componenti evidenziate grazie al supporto di strumenti avanzati di analisi e l'introduzione di nuove piante modello (Inan et al., 2004). Oggi sappiamo che esistono signal transduction pathway paralleli che possono essere attivati da più stress e possono comunicare tra loro per coordinare simultaneamente più risposte di adattamento (Chinnusamy et al., 2004; Orsini et al., 2010d). La sovrapproduzione di molecole a valle (Chinnusamy et al., 2005) del pathway di trasduzione del segnale di stress e successivamente a monte (Guo et al., 2002) ha portato alla prima e alla seconda generazione di piante transgeniche con maggiore tolleranza a vari stress ambientali, inclusi quello salino. Nelle specie ortive il potenziamento della tolleranza agli stress ambientali è stato ottenuto, per la salinità, attraverso il controllo dell'omeostasi ionica (Zhang e Blumwald, 2001; Rus et al., 2001). Tuttavia in tutti questi casi, l'evidenza sperimentale è rimasta generalmente a livello di proof-of-concept non raggiungendo quasi mai lo stadio di technology transfer in pieno campo. Se da un lato questi target non si sono rivelati poi così efficaci al di là della sperimentazione di laboratorio, è pur vero che i maggiori investimenti privati nel settore biotecnologie sono al momento indirizzati a colture erbacee estensive (Chinnusamy et al., 2005) che possano garantire maggiori ritorni economici. Non a caso la prima pianta transgenica ad elevata tolleranza allo stress idrico ad essere prossimamente introdotta sul mercato sarà una varietà di mais che sovra-esprime il fattore di trascrizione ZmNF-YB2 precedentemente isolato in Arabidopsis attraverso un approccio di genomica funzionale (Nelson et al., 2007).

Negli ultimi anni c'è stato un interesse crescente verso l'identificazione dei sensori dello stress cioè quelle molecole in grado di percepi- re la presenza di stress ed attivare simultaneamente più pathway di adattamento (Munns, 2002; Thomashow, 1999). Sensori dello stress sono stati individuati nei cianobatteri, Bacillus subtilis e Saccaromyces cerevisiae (Suzuky et al., 2000; Aguilar et al., 2001). In pianta, questa funzione è stata attribuita ad un'istidina chinasi AThkt1 isolata in Arabidospsis (Urao et al., 1999) ed un recettore protein-chinasi isolato in tabacco (Tamura et al., 2003).

Di recente sono stati ottenuti risultati promettenti in relazione alla funzione dei recettori dell'ABA, un regolatore fondamentale dell'adattamento a stress biotici ed abiotici (Zhu, 2002; Fujita et al., 2006). Molti aspetti della biosintesi, trasporto, metabolismo ed effetti dell'ABA sulla trascrizione di geni essenziali per l'adattamento sono stati studiati in dettaglio (Verslues e Zhu, 2007; Klingler et al., 2010), ma solo negli ultimi anni è stata isolata una nuova classe di ABA-binding proteins inequivocabilmente identificata come recettori dell'ABA in grado di interagire chimicamente con questo ormone ed innescare l'attivazione dei molteplici processi da esso mediati (Klingler et al., 2010). Questa famiglia di recettori, e le complesse interazioni associate alle loro modalità d'azione, potrebbero aprire nuove prospettive per modificare i livelli di percezione dell'ABA attraverso breeding convenzionale 0 basato sulle tecnologie del DNA ricombinante (piante geneticamente modificate) al fine di ottenere un maggiore controllo in campo delle risposte mediate dall'ABA.

Un ultimo riferimento va fatto all'uso di piante modello per lo studio dei meccanismi fisiologico-molecolari di tolleranza allo stress salino ed abiotico in genere. Tra queste, Arabidopsis ha avuto un ruolo essenziale per progredire in questo settore (Maggio et al., 2004). Inoltre, l'introduzione di Arabidopsis Relative Model Systems (ARMS) ha messo a disposizione sistemi più avanzati che associano alle caratteristiche di Arabidopsis specificità tipiche delle extremophiles cioè di piante con spiccate caratteristiche di tolleranza ad ambienti estremi (Inan et al., 2004). L'uso di modelli geneticamente vicini ad Arabidopsis ha il vantaggio di poter isolare più efficientemente le componenti di risposta, tolleranza e adattamento allo stress. L'alofita Thellungiella halophila, naturalmente tollerante concentrazioni di sale fino a $400 \mathrm{mM} \mathrm{NaCl}$ può convertirsi da alofita in glicofita (Arabidopsis) attraverso la modifica di uno (o pochi) geni indicando, viceversa, che la tolleranza di una glicofita a elevate concentrazioni di sale può essere aumentata modificando uno (o pochi) geni chiave per l'adattamento (Inan et al., 2004). Correntemente si stanno valutando le potenzialità di altri sistemi modello che possano consentire di effettuare valutazioni comparative a livello fisiologico, molecolare e genomico (Orsini et al., 2010).

Va infine ricordato che un'area in forte espansione è lo studio delle modifiche epigenetiche che durante l'adattamento alle mutevoli condizioni ambientali consentono di adattare e riprogrammare crescita e sviluppo per completare il ciclo biologico (Chinnusamy e Zhu, 2009). Molte di queste modifiche indotte da stress (modifiche istoniche post-trasduzionali e metilazione del DNA) possono avere carattere transitorio e vengono risettate quando si ristabiliscono condizioni ottimali di crescita, ma alcune possono essere stabili/permanenti e costituire una sorta di stress memory trasferita all'interno di una generazione 0 in generazioni successive, attraverso divisione mitotica o meiotica (Zhu, 2009).

\section{Creazione di varietà adatte ad una coltivazione sostenibile}

Non c'è dubbio sul fatto che la rivoluzione verde e con essa il breeding condotto nel XX secolo hanno portato ad un aumento spettacolare delle rese produttive (Figura 2). È altrettanto chiaro, tuttavia, che le varietà licenziate negli ultimi 100 anni hanno comportato una dipendenza sempre più elevata dell'agricoltura da fattori della produzione energeticamente costosi (fertilizzanti, macchine ecc.) e un'enorme dipendenza dai 
pesticidi, necessari per il controllo delle malattie (Figura 2). Per quanto riguarda l'impiego di fertilizzanti, questo è passato dai 31,2 milioni di tonnellate del 1961 a poco più di 140 milioni di tonnellate degli anni ' 90 , quando i consumi a livello mondiale si sono apparentemente stabilizzati. Per quanto riguarda invece i dati riguardanti l'impiego di pesticidi, che secondo la terminologia anglosassone comprendono diserbanti, insetticidi e anticrittogamici, dati frammentari indicano che nel periodo considerato il consumo di pesticidi è cresciuto di un ordine di grandezza, passando da 0,1 a oltre 1 milione di t/anno attorno agli anni ' 904 . Il tutto si è tradotto in costi crescenti per l'agricoltore e nell'insostenibilità ambientale per molte agricolture, tra cui quella europea.

La Politica Agricola Comunitaria (PAC), in particolare Agenda 2000, ha posto il problema della non sostenibilità di tale evoluzione, definendo tra le linee prioritarie di indirizzo: i) la riduzione degli input energetici e ii) la riduzione dell'uso dei pesticidi (prodotti utilizzati per il controllo di patogeni, parassiti e malerbe). Le ragioni di tale politica sono la ridefinizione delle pratiche agricole nell'ambito di un'adeguata sostenibilità ambientale e l'attenzione alla salute dei consumatori.

Il breeding si è così avviato finalmente verso ideotipi più adatti alla nuova visione dell'agricoltura: ideotipi in grado di utilizzare con maggiore efficienza i fattori della produzione (es. acqua e nutrienti) e in grado di adattarsi ad ambienti più marginali, come aree sub-aride e suoli alcalino-salini, che rappresentano una percentuale significativa delle aree potenzialmente utilizzabili all'agricoltura; ideotipi in grado di convertire con maggiore efficienza l'energia catturata in prodotti utili e in grado di resistere ai principali patogeni e parassiti.

Per quanto riguarda la riduzione degli input energetici, un'importante linea di attività del breeding attuale è la ricerca di una maggior efficienza nell'utilizzazione dell'azoto (Good et al., 2008), che si può tradurre in considerevoli risparmi nell'impiego di tale fertilizzante a beneficio dell'agricoltore e dell'ambiente in cui opera. Una seconda linea di lavoro è la ricerca di genotipi adatti a sopportare ridotte disponibilità idriche (Nelson et al., 2007). Infine, un terzo campo di notevole impatto sull'agricoltura riguarda l'uso di genotipi adatti a suoli ad elevato contenuto salino, in particolare suoli con elevata presenza di $\mathrm{NaCl}$ (Xia et al., 2002). Si calcola che ogni anno l'agricoltura mondiale perda 800.000 ha a causa di una progressiva salinizzazione dei terreni (vedi sezione Sostenibilità delle produzioni in ambiente salino). La creazione di piante resistenti a stress idrici e salini in campo ortofrutticolo è ancora agli albori, ma l'elevata mole di ricerche compiute in piante modello come riso, tabacco e Arabidopsis fanno sperare nell'estensione in tempi brevi di molti risultati promettenti perlomeno al campo delle orticole.

Un altro obiettivo generale del breeding attuale (ma non solo) è l'introduzione della resistenza a patogeni e parassiti. Per i secondi, le resistenze nelle specie vegetali sono piuttosto rare; per cui il controllo dei parassiti è spesso ottenuto con la lotta biologica tramite l'uso di antagonisti/predatori e tecniche di confusione sessuale.

Nel campo delle resistenze, l'attività dei breeders è stata lunga e intensa e quindi gli esempi sono numerosi sia nel campo dei cereali, che in quello delle colture industriali e ortofrutticole. Ci piace ricordare che lo stesso Vavilov, lo scienziato che dedicò la propria vita all'esplorazione della diversità genetica e che - primo tra tutti - introdusse il concetto che la diversità genetica è massima nei centri di origine delle specie, iniziò la propria attività di ricercatore studiando i rapporti ospite-patogeno e intuendo che la resistenza di una pianta al proprio patogeno è sotto controllo genetico (Vavilov, 1914; Loskutov, 1999).

Ricordiamo alcuni esempi di successo che stanno contribuendo significativamente alla riduzione dei pesticidi di sintesi. La resistenza del fagiolo all'antracnosi (Colletotrichum lindemuthianum) è emblematica del gran lavoro svolto dai breeders. Nel fagiolo comune sono stati identificati finora 13 geni di resistenza ad antracnosi (12 se si considera che $\mathrm{Co}$ 3 e $\mathrm{Co}^{-} 9$ sono allelici), che vengono regolarmente combinati assieme - 0 piramidati come si dice tra gli addetti ai lavori - per far fronte ad un patogeno ad elevata variabilità genetica, nel quale sono state classificate finora ben 100 razze (Kelly e Vallejo 2004; Campa et al. 2009). Una situazione analoga si riscontra sul melo, dove varietà portanti resistenze singole sono sul mercato dagli anni '70 del secolo scorso, ma nel quale i breeders per ovviare al superamento delle resistenze singole da parte di razze diverse del patogeno, hanno recentemente combinato insieme fino a 5 diversi geni di resistenza a Venturia nello stesso genotipo (Gessler et al. 2006, Kellerhals et al. 2007).

Vale la pena ricordare, infine, la storia ultra-centenaria del miglioramento genetico della patata per la resistenza a peronospora (Phytophthora infestans). I ricercatori, dopo avere lavorato per decine di anni con geni razza-specifici di Solanum demissum, hanno solo recentemente ottenuto la possibilità di coltivazione di patate GM portanti i geni Rpi-blb ed Rpi-blb2, ottenuti da S. bulbocastanum e caratterizzati da resistenza ad un ampio spettro di isolati del patogeno (Vleeshouwers et al., 2008). Gli esempi potrebbero continuare. Tuttavia ci preme fare un'altra considerazione. Come appare evidente dalla Tabella 2, alcune delle fonti

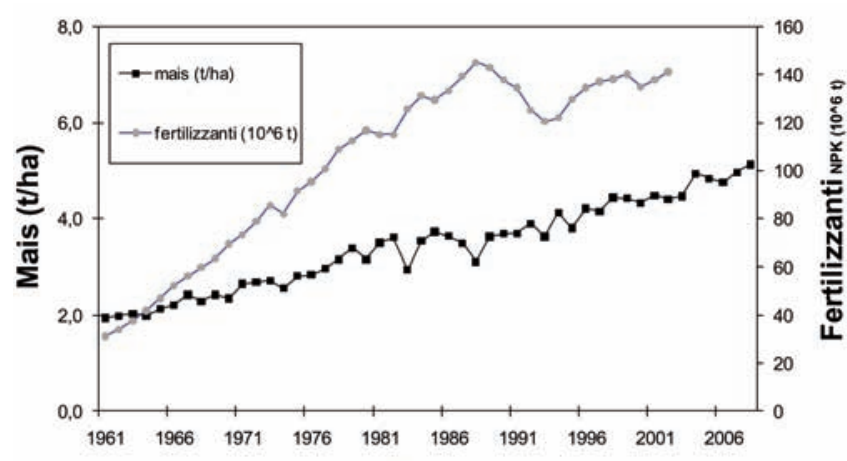

Anno

Figura 2. Evoluzione delle rese del mais negli ultimi decenni ed evoluzione dell'impiego di fertilizzanti (NPK) in agricoltura nello stesso periodo (Fonte: FAOSTAT 2010).

Figure 2. Mais yield and fertilisers use in the last decades (source: FAOSTAT, 2010).

Tabella 2. Esempi di specie ortofrutticole per le quali l'introduzione di geni di resistenza ha determinato una sensibile riduzione del fabbisogno di pesticidi.

Table 2. Examples of successful transfer of disease tolerance genes in vegetable crops and fruit trees, which caused a significant reduction of pesticides applications.

\begin{tabular}{|c|c|c|c|}
\hline Specie & Malattia (patogeno) & Geni utilizzati (fonte) & Riferimento bibliografico \\
\hline $\begin{array}{l}\text { Fagiolo } \\
\text { Melo }\end{array}$ & $\begin{array}{l}\text { Antracnosi (Colletotrichum lindemuthianum) } \\
\text { Ticchiolatura (Venturia inequalis) }\end{array}$ & $\begin{array}{l}\text { Co-1 a Co-13 (P. vulgaris) } \\
\text { Va (Antonovkà complex), Vb (M. baccata), Vbj } \\
\text { (M. baccata jackii), Vf (M. floribunda), } \\
\text { Vm (M. micromalus), Vr (M. pumila) e altri }\end{array}$ & $\begin{array}{l}\text { Kelly e Vallejo 2004; Campa et al. } 2009 \\
\text { Gessler et al. } 2006\end{array}$ \\
\hline Papaya & Papaya ringspot virus (PRSV) & PRSV-cp (papaya ringspot virus) & Tecson Mendoza et al. 2008 \\
\hline Patata & Peronospora (Phytophthora infestans) & Rpi-blb1, Rpi-blb2 (bulbocastanum) & Vleeshouwers et al. 2008 \\
\hline
\end{tabular}


di resistenza vengono da genotipi wild 0 da specie selvatiche affini e le linee utili al breeder vengono dalle grosse collezioni di germoplasma e ovviamente, per quanto non ancora esplorato, dai centri di origine delle diverse specie.

Gli Stati Uniti nel 1990 hanno compiuto uno sforzo enorme, organizzativo e finanziario, per riordinare le proprie collezione genetiche, dando vita al NGRP (National Genetic Resources Program) ${ }^{6}$ e attraverso lo strumento del GRIN (Germplasm Resources Information Network) hanno messo a disposizione della comunità scientifica e dei breeders privati l'immenso patrimonio raccolto in oltre 300 anni di attività. Anche fuori dagli USA, istituzioni internazionalmente riconosciute come il CYMMIT ${ }^{7}$ del Messico o l'IPK ${ }^{8}$ tedesco operano allo stesso modo. Tuttavia, la Convenzione di Rio sulla salvaguardia delle risorse genetiche (1992) ha paradossalmente stimolato una sorta di chiusura da parte di molti paesi detentori di risorse genetiche allo scambio di germoplasma, che rappresentava una conquista della comunità scientifica internazionale. Le ragioni di tale chiusura vanno ricercate nella volontà di difendere il proprio germoplasma dalla politica aggressiva delle multinazionali del farmaco che raccolgono germoplasma gratuitamente nei paesi in via di sviluppo e brevettano i principi attivi nelle nuove varietà che producono. Le preoccupazioni sono condivisibili, le richieste di rendite di posizione a vita per le popolazioni che abitano casualmente le aree di origine del germoplasma non altrettanto. La parola chiave per un accordo è mutual benefit. In altre parole l'utilizzo delle risorse genetiche deve essere a beneficio di chi le possiede e di chi le utilizza. Nel primo caso il beneficio deve creare condizioni di sviluppo, non certamente rendite assistenziali che perpetuerebbero le condizioni di sottosviluppo. Un secondo aspetto del problema riguarda la distinzione tra prodotti di interesse farmaceutico e prodotti di interesse alimentare, soprattutto se si tratta di colture importanti nell'alimentazione umana (staple food). Nel primo caso i margini per remunerare i detentori delle risorse sono ampi; nel secondo caso i margini per tale operazione sono sensibilmente più ridotti. Anche di questo è necessario tenere conto.

Delle restrizioni imposte dalle politiche nazionali all'utilizzo di germoplasma, di cui un esempio è rappresentato dalla Cina, soffrono colture di più recente addomesticamento come l'actinidia, ma anche grandi colture come il caffè, il thè o la banana. La diversità genetica è la base del breeding e la scarsità di fonti genetiche di resistenza espone le colture a pericoli di malattie, capaci di minacciare la stessa esistenza della specie nelle aree dove questa è largamente coltivata senza essere una specie nativa. Sono esempi recenti le coltivazioni di papaya devastate da Papaya ringspot virus (PRSV) o le coltivazioni di banana tornate sensibili a Fusarium oxysporum (Panama disease).

Diceva Darwin che nel mondo gli organismi viventi devono lottare per sopravvivere, adattandosi continuamente al mutare delle condizioni di vita. La biblioteca cui attingono per adattarsi è la diversità genetica. Alla stessa preziosa biblioteca attingono i breeders.

\footnotetext{
${ }^{6}$ http://www.ars-grin.gov/

${ }^{7}$ http://www.cimmyt.org

${ }^{8}$ www.ipk-gatersleben.de/
}

\section{Conclusioni}

La definizione di sistemi ortofrutticoli sostenibili, in linea con le indicazioni europee per la salvaguardia ambientale e l'uso efficiente delle risorse, non potrà essere che il risultato di maggiori investimenti in ricerca applicata e di base con un approccio integrato che guardi con attenzione al trasferimento tecnologico. L'applicazione di tecnologie consolidate a realtà colturali in evoluzione, come quelle dell'agricoltura urbana, è solo un esempio di un possibile technology transfer che consentirebbe di migliorare la gestione delle risorse in spazi limitati (aumento dell'efficienza d'irrigazione, riduzione dell'uso di agrofarmaci e dell'impatto dell'attività orticola su salute umana e ambiente), sviluppando allo stesso tempo importanti economie locali. Similmente, nelle aree esposte a salinizzazione l'implementazione di tecnologie conservative che, limitando i danni alle colture, siano in grado di controllare il deterioramento dei suoli apporterebbe vantaggi di breve e medio-periodo. Un terzo strumento di sviluppo sostenibile è rappresentato dal breeding che, utilizzando la mole di conoscenze che si stanno accumulando nei campi della fisiologia, della biologia e della genetica molecolare e le nuove tecnologie di breeding assistito dalle informazioni molecolari e le tecnologie del DNA ricombinante può dar vita a programmi di incrocio tradizionale e/o ingegneria genetica disegnati ad hoc per garantire, in ultima analisi, una sostenibilità di lungo periodo.

\section{Bibliografia}

Abdelly C., Öztürk M., Ashraf M., Grignon C., 2008. Biosaline agriculture and high salinity tolerance. Springer Verlag, Basel, Switzerland. Agrawal M., Singh B., Rajput M., Marshall F., Bell J., 2003. Effect of air pollution on peri-urban agriculture: a case study. Environ. Pollution 126:323-329.

Aguilar P., Hernandez-Arriaga A.M., Cybulski L.E., Erazo A.C., de Mendoza D., 2001. Molecular basis of thermosensing: a two-component signal transduction thermometer in Bacillus subtilis EMBO J. 20:1681-1691.

Alexandratos N., 1999.World food and agriculture: outlook for the medium and longer term. Proc. Natl. Acad. Sci. USA 96:5908-5914.

Altieri M.A., Companioni N., Canizares K., Murphy C., Rosset P., Bourque M., Nicholls C., 1999. The greening of the 'Barrios': Urban agriculture for food security in Cuba. Agr. Hum. Val. 16:131-140.

Alvarado A.D., Bradford K.J., Hewitt J.D., 1987. Osmotic priming of tomato seeds. Effects on germination, field emergence, seedling growth and fruit yield. J. Am. Soc. Hort. Sci. 112:427-432.

Amzallag G.N., 2002. The adaptive potential of plant development: evidence from the response to salinity. In: A. Lauchli and U. Luttge (eds.) Salinity: Environment-Plants-Molecules. Kluwer Academic Publ., Dordrecht, The Netherlands.

Amzallag G.N., Lerner, H.R., Poljakoff-Mayber, A., 1990. Induction of increased salt tolerance in Sorghum bicolor by $\mathrm{NaCl}$ pretreatment. J. Exp. Bot. 41:29-34.

Armar-Klemesu M., 2000. Urban agriculture and food security, nutrition and health. In: N. Bakker, M. Dubbeling, S. Guendel, U. SabelKoschella and H. de Zeeuw (eds.) Growing cities, growing food, urban agriculture on the policy agenda. DSE Ppubl., Feldafing Germany.

Ayers R.S., Westcot D.W., 1994. Water quality for agriculture. FA0 Irrigation and Drainage Paper 29 Rev.1. Available from: http://www.fao.org/DOCREP/003/T0234E/ T0234E00.HTM

Bartels D., Phillips J., 2010. Genetic modification of plants. Biotech. Agr. Forestry 64:139-157.

Bartels D., Sunkar R., 2005. Drought and salt tolerance in plants. Crit. Rev. Plant Sci. 24:3-58.

Bayon R., Jenkins M., 2001. The business of Biodiversity. Nature 466:184-185.

Buechler S., Devi Mekala G., Keraita B., 2006. Wastewater use for urban and peri-urban agriculture. In: R. van Veenhuizen (ed.) Cities farming for the future, urban agriculture for green and productive cities. RUAF Foundation, IDRC and IIRR, Silang, The Philippines. Available from: http://www.ruaf.org/node/961

Campa A., Giraldez R., Ferreira J.J., 2009. Genetic dissection of the resistance to nine anthracnose races in the common bean differential 
cultivars MDRK and TU. Theor. Appl. Genet. 119:1-11.

Cano E.A., Bolarõn, M.C., Perez-Alfocea F., Caro M., 1991. Effect of NaCl priming on increased salt tolerance in tomato. J. Hort. Sci. 66:621628.

Cassman K. G., 1991. Ecological intensification of cereal production systems: yield potential, soil quality, and precision agriculture. Proc. Natl. Acad. Sci. USA 96:5952-5959.

Chinnusamy V., Jagendorf A., Zhu J.K., 2005. Understanding and improving salt tolerance in plants. Crop Sci. 45:437-448.

Chinnusamy V., Schumaker K., Zhu J.K., 2004. Molecular genetic perspectives on cross-talk and specificity in abiotic stress signalling in plants. J. Exp. Bot. 55:225-236.

Chinnusamy V., Zhu J.K., 2009. Epigenetic regulation of stress responses in plants. Curr. Opin. Plant Biol. 12:133-139.

Cofie 0., Bradford A.A., Dreschel P., 2006. Recycling of urban organic waste for urban agriculture. In: In: R. van Veenhuizen (ed.) Cities farming for the future, urban agriculture for green and productive cities. RUAF Foundation, IDRC and IIRR, Silang, The Philippines. Available from: http://www.ruaf.org/node/961

Copeman R.H., Martin C.A., Stutz J.C., 1996. Tomato growth in response to salinity and mycorrhizal fungi from saline or non-saline soils. HortScience 31:341-344.

Cruz M.C., Medina R.S., 2003. Agriculture in the city: a key to sustainability in Havana, Cuba. Ian Randle Publ., Kingston, Jamaica. Available (http//www.idrc.ca/openebooks/104-3/).

Cuartero J., Fernandez-Munoz R. 1999. Tomato and salinity. Sci. Hortic. 78:83-125.

Dalton F.N., Maggio A., Piccinni G., 2000. Simulation of shoot chloride accumulation, separation of physical and biochemical processes governing plant salt tolerance. Plant Soil 219:1-11.

Danso G., Drechsel P., Wiafe-Antwi T,. Gyiele L., 2002. Income of farming systems around Kumasi, Ghana. Urban Agriculture Magazine 7:5-6.

De Pascale S., Dalla Costa L., Vallone S., Barbieri G., Maggio A., 2011. Increasing water use efficiency in vegetable crop production: from plant to irrigation systems efficiency. HorTech. in stampa.

De Pascale S., Maggio A., 2008. Plant stress management in semiarid greenhouse. Acta Hort. 797:205-215.

De Pascale S., Maggio A., Barbieri G., 2005. Soil salinization affects growth, yield and mineral composition of cauliflower and broccoli. Eur. J. Agron. 23:254-264.

De Pascale S., Ruggiero C., Barbieri G., Maggio A., 2003. Physiological response of pepper (Capsicum annuum L.) to salinity and drought. J. Amer. Soc. Hort. Sci. 128:48-54.

Deesohu Saydee G., Ujereh S., 2003. Rooftop gardening in Senegal. Urban Agriculture Magazine 10:16-17.

Drescher A.W., 2004. Food for the cities: urban agriculture in developing countries. Acta Hort. 643:227-231.

Eumorphopoulos E., Aravantinos D., 1998. The contribution of a planted roof to the thermal protection of buildings in Greece. Energ. Buildings 27:20-36.

European Commission, 2009. New challenges for agricultural Research: climate change, food security, rural development, agricultural knowledge systems, 2nd SCAR foresight exercise. Available

from: http://ec.europa.eu/research/agriculture/scar/pdf/publication_ 2nd_SCAR_foresight_exercise.pdf

European Science Foundation, 2009. European Food Systems in a Changing World. Available from: http://www.esf.org/index.php?id=728

Fedoroff N.V., Battisti D.S., Beachy R.N., Cooper P.J.M., Fischhoff D.A., Hodges C.N., Knauf V.C., Lobell D., Mazur B.J., Molden D., Reynolds M.P., Ronald P.C., Rosegrant M.W., Sanchez P.A., Vonshak A., Zhu J.K., 2010. Radically rethinking agriculture for the 21st cen- tury. Science 327:833-834.

Fujita M., Fujita Y., Noutoshi Y., Takahashi F., Narusaka Y., YamaguchiShinozaki K., Shinozaki K., 2006. Crosstalk between abiotic and biotic stress responses: a current view from the points of convergence in the stress signalling networks. Curr. Opin. Plant Biol. 9:436-442.

Gessler C., Patocchi A., Sansavini S., Tartarini S., Gianfranceschi L., 2006. Venturia inaequalis resistance in apple. Crit. Rev. Plant Sci. 25:473-503.

Gianquinto G., Michelon N., Orsini F., 2007a. Idroponia in un area povera del nord est del Brasile. Un esempio di cooperazione decentrata. Regione Veneto-FA0. In: G. Franceschetti (ed.) Agricoltura e ruralità nei paesi ad economia povera. Collana "I Percorsi dello Sviluppo". CLEUP, Padova, Italy.

Gianquinto G., Orsini F., Michelon N., Ferreira Da Silva D., Damasio De Faria F., 2007b. Improving yield of vegetables by using soilless micro-garden technologies in peri-urban area of North-East Brazil. Acta Hort. 747:57-65.

Gianquinto G., Tei F., 2010. Orticoltura Urbana nei Paesi in Via di Sviluppo: ruolo multifunzionale, sistemi colturali e prospettive future. Italus Hortus 17:71-97.

Good A.G., Johnson S.J., De Pauw M., Carroll R.T., Savidov N., Vidmar J., Lu Z., Taylor G., Stroeher V., 2007. Engineering nitrogen use efficiency with alanine aminotransferase. Can. J. Bot. 85:252-262.

Guo Y., Xiong L., Song C.P., Gong D., Halfter U., Zhu J.K., 2002. A calcium sensor and its interacting protein kinase are global regulators of abscisic acid signaling in Arabidopsis. Dev. Cell 3:233-244.

Hachicha, M., Cheverry, C., Mhiri, A., 2000. The impact of longterm irrigation on changes of ground water level and soil salinity in northern Tunisia. Arid Soil Res. Rehab. 14:175-182.

Hirrel, M.C., Gardemann, J.W., 1980. Improved growth of onion and bellpepper in saline soils by two vesicular-arbuscular mycorrhizal fungi. Soil Sci. Soc. Am. J. 44:654-655.

Holmer R.J., Clavejo M.T., Dongus S., Drescher A., 2003. Allotment gardens for Philippine cities. Urban Agriculture Magazine 11:29-31.

Hu X.J., Zhang Z.B., Xu P., Fu Z.Y., Hu S.B., Song W.Y., 2010. Multifunctional genes: the cross-talk among the regulation networks of abiotic stress responses. Biol. Plantarum 54:213-223.

Inan G., Zhang Q., Li P., Wang Z., Cao Z., Zhang H., Zhang C., Quist T.M., Goodwin S.M., Zhu J., Shi H., Damsz B., Charbaji T., Gong Q., Ma S., Fredricksen M., Galbraith D.W., Jenks M.A., Rhodes D., Hasegawa P.M., Bohnert H.J., Joly R.J., Bressan R.A., Zhu J.K., 2004. Salt cress. A halophyte and cryophyte Arabidopsis relative model system and its applicability to molecular genetic analyses of growth and development of extremophiles. Plant Physiol. 135:17181737.

Izquierdo J., 2006. Simplified Hydroponics, a tool for food security in Latin America and the Caribbean. FAO Regional Office for Latin America and the Caribbean.

Kelly J.D., Vallejo V.A., 2004. A comprehensive review of the major genes conditioning resistance to anthracnose in common bean. HortScience 39:1196-1207.

Klingler J.P., Batelli G., Zhu J.K., 2010. ABA receptors: the START of a new paradigm in phytohormone signaling. J. Exp. Botany 61:31993210 .

Loskutov I.G., 1999. Vavilov and his institute. A history of the world collection of plant genetic resources in Russia. International Plant Genetic Resources Institute, Roma, Italy.

Maas E.V., Grattan S.R., 1999. Crop yields as affected by salinity. In: R.W. Skaggs and J. van Schilfgaarde (eds.) Agricultural Drainage. Agron. Monogr. 38. Amer. Soc. Agron. Publ., Madison, WI, USA.

Maggio A., De Pascale S., Fagnano M., Barbieri G., 2011. Saline agriculture in mediterranean environments. Ital. J. Agron. 6:e7.

Maggio A., De Pascale S., Ruggiero C., Barbieri G., 2005. Physiological 
response of field-grown cabbage to salinity and drought stress. Eur. J. Agron. 23:57-67.

Maggio A., Hasegawa P.M., Bressan R.A., Consiglio M.F., Joly R.J., 2001. Unravelling the functional relationship between root anatomy and stress tolerance. Aust. J. Plant Physiol. 28:999-1004.

Maggio A., Joly R.J., Hasegawa P.M., Bressan R.A., 2002. Can the quest for drought tolerant crops avoid Arabidopsis any longer? In: S.S. Goyal, S.K. Sharma and D.W. Rains (eds.) Crop production under saline environments: global and integrative perspectives. J. Crop Prod. 7:99-129.

Maggio A., Raimondi G., Martino A., De Pascale S., 2007. Salt stress response in tomato the salinity tolerance threshold. Env. Exp. Botany 59:276-282.

Maggio A., Zhu J.K., Hasegawa P.M., Bressan R.A., 2006. Osmogenetics: Aristotle to Arabidopsis. Plant Cell 18:1542-1557.

Marulanda C., Izquierdo J., 2003. Manual tecnico: La huerta hidroponica popular. Curso audiovisual. Oficina Regional para America Latina y el Caribe, FA0, Santiago, Chile.

Masle J., Gilmore S.R., Farquhar G.D., 2005. The ERECTA gene regulates plant transpiration efficiency in Arabidopsis. Nature 436:866870.

Mavrogianopoulos G., Vogli V., Kyritsis S., 2002. Use of wastewater as a nutrient solution in a closed gravel hydroponic culture of giant reed (Arundo donax). Bioresource Technology, 82:103-107.

Morant M., Ekstrøm C., Ulvskov P., Kristensen C., Rudemo M., Olsen C.E., Hansen J., Jørgensen K., Jørgensen B., Møller B.L., Bak S. 2010. Metabolomic, Transcriptional, Hormonal, and Signaling Cross-Talk in Superroot2. Mol. Plant 3:192-211.

Mougeot L.J.A., 2005. Urban agriculture and the Millennium Development Goals. In: L.J.A. Mougeot (ed.) AGROPOLIS. The social, political and environmental dimensions of urban agriculture. Earthscan Publ., London, UK.

Moya J.L., Primo-Millo E., Talon, M., 1999. Morphological factors determine salt tolerance in citrus seedlings: the shoot to root ratio modulates passive root uptake of chloride ions and their accumulation in leaves. Plant Cell Environ. 22:1425-1433.

Müller K.0., Black W., 1952. Potato breeding for resistance to blight and virus diseases during the last hundred years. Z. Pflanzenzuchtung $31: 305-318$.

Munns R., 2002. Comparative physiology of salt and water stress. Plant Cell Environ. 25:239-250.

Murphy C., 1999. Cultivating Havana: urban agriculture and food security in the years of crisis. Development Report No.12, Food First. Institute for Food and Development Policy. Available from: http://www.foodfirst.org/en/node/273.

Nelson D.E., Repetti P.P., Adams T.R., Creelman R.A., Wu J., Warner D.C., Anstrom D.C., Bensen R.J., Castiglioni P.P., Donnarummo M.G., Hinchey B.S., Kumimoto R.W., Maszle D.R., Canales R.D., Krolikowski K.A., Dotson S.B., Gutterson N., Ratcliffe 0.J., Heard J.E., 2007. Plant nuclear factor Y (NF-Y) B subunits confer drought tolerance and lead to improved corn yields on water-limited acres. Proc. Natl. Acad. Sci. USA 104:16450-16455.

Novo M.G., Murphy C., 2000. Urban agriculture in the city of Havana: a popular response to crisis. In: N. Bakker, M. Dubbeling, S. Guendel, U. Sabel Koschella and H. de Zeeuw (eds.) Growing cities, growing food, urban agriculture on the policy agenda. DSE Publ., Feldafing, Germany.

Organisation for Economic Co-operation and Development, 2007. Biofuels: is the cure worse than the disease? Round Table on Sustainable Development. OECD Publ., Paris, France. Available from: http://www.oecd.org/dataoecd/9/3/39411732.pdf

Orsini F., Cascon P., De Pascale S., Barbieri G., Corrado G., Rao R., Maggio A., 2010a. Systemin-dependent salinity tolerance in tomato: evidence of specific convergence of abiotic and biotic stress responses. Physiol. Plant. 138:10-21.

Orsini F., Fecondini M., Mezzetti M., Gianquinto G., 2010a. Simplified hydroponic floating systems for vegetable production in Trujillo, Peru. Proc. 2nd ISHS Int. Conf. Landscape and Urban Horticulture, Bologna, Italy.

Orsini F., Mezzetti M., Fecondini M., Gianquinto G., 2010b. Simplified substrate soilless culture for vegetable production in Trujillo, Peru. Proc. 2nd ISHS Int. Conf. Landscape and Urban Horticulture, Bologna, Italy.

Orsini F., Morbello M., Fecondini M., Gianquinto G., 2010c. Hydroponic gardens: undertaking malnutrition and poverty through vegetable production in the suburbs of Lima, Peru. Proc. 2nd ISHS Int. Conf. Landscape and Urban Horticulture, Bologna, Italy.

Orsini F., Paino D'Urzo M., Inan G., Serra S., Oh D.H., Mickelbart M.V., Consiglio F., Li X., Jeong J.C., Yun D.J., Bohnert H.J., Bressan R.A., Maggio A., 2010d. A comparative study of salt tolerance parameters in 11 wild relatives of Arabidopsis thaliana. J. Exp. Bot. 61:37873798.

Pardo J.M., 2010. Biotechnology of water and salinity stress tolerance. Curr. Opin. Biotechnol. 21:185-196.

Pardossi A., Malorgio F., Oriolo D., Gucci R., Serra G., Tognoni F., 1998. Water relations and osmotic adjustment in Apium graveolens during long-term $\mathrm{NaCl}$ stress and subsequent relief. Physiol. Plant. 102:369-376.

Pathak R.R., Ahmad A., Lochab S., Raghuram N. 2008. Molecular physiology of plant nitrogen use efficiency and biotechnological options for its enhancement. Curr. Sci. 94:1394-1403.

Prain G., 2006. Integrated urban management of local agricultural development: the policy arena in Cuba. In: R. van Veenhuizen (ed.) Cities farming for the future, urban agriculture for green and productive cities. RUAF Foundation, IDRC and IIRR, Silang, The Philippines. Available from: http://www.ruaf.org/node/961

Rhoades J.D., Kandiah A., Mashali A.M., 1992. The use of saline waters for crop production. FAO - Irrigation and Drainage paper 48. Available from: http:/www.fao.org/nr/water/infores_databases_cropwat.html

Rodríguez-Delfín A., 2008. Legumes: Hydro holds hope for developing nations. The Growing Edge 19:42-46.

Rodríguez-Delfín A., Chang M., Hoyos M., Falcón F., 2004. Manual Práctico de Hidroponía. 4ta ed. Centro de Investigación de Hidroponía y Nutrición Mineral. Universidad Nacional Agraria La Molina Publ., Lima, Peru.

Rosset P., Benjamín M., 1994. The greening of the revolution. Cuba's Experiment with Organic Agriculture. Ocean Press, Melbourne, Australia.

Rozema J., Flowers T., 2008. Crops for a Salinized World. Science 322:1478-1480.

Ruggiero B., Koiwa H., Manabe Y., Quist T.M., Inan G., Saccardo F., Joly R.J., Hasegawa P.M., Bressan R.A., Maggio A. 2004. Uncoupling the Effects of ABA on Plant Growth and Water Relations: Analysis of sto1/nced3, ABA Deficient Salt Stress Tolerant Mutant in Arabidopsis thaliana. Plant Physiol. 136:3134-3147.

Rus A.M., Estan M.T., Gisbert C., Garcia-Sogo B., Serrano R., Caro M., Moreno V., Bolarin C.A., 2001. Expressing the yeast HAL1 gene in tomato increases fruit yield and enhances $\mathrm{K}+/ \mathrm{Na}+$ selectivity. Plant Cell Environ. 24:875-880.

Sakamoto A., Murata N., 2002. The role of glycine betaine in the protection of plants from stress: clues from transgenic plants. Plant Cell Environ. 25:163-171.

Shariful Islam K.M., 2004. Rooftop gardening as a strategy of urban agriculture for food security: the case of Dhaka City, Bangladesh. Acta Hort. 643:241-247.

Suzuki I., Los D.A., Kanesaki Y., Mikami K., Murata N., 2000. The pathway for perception and transduction of low-temperature 
signals in Synechocystis. EMBO J. 19:1327-1334.

Tamura T., Hara K., Yamaguchi Y., Koizumi N., Sano H., 2003. Osmotic stress tolerance of transgenic tobacco expressing a gene encoding a membrane-located receptor-like protein from tobacco plants. Plant Physiol. 131:454-462.

Tecson Mendoza E.M., Laurena A.C., Botella J.R., 2008. Recent advances in the development of transgenic papaya technology. Biotechnol. Ann. Rev. 14:423-462.

The Royal Society, 2009. Reaping the benefits: Science and the sustainable intensification of global agriculture. Available from: http://royalsociety.org/Reapingthebenefits/

Thomashow M.F., 1999. Plant cold acclimation: freezing tolerance genes and regulatory mechanisms. Ann. Rev. Plant. Biol. 50:571599.

Thompson A.J., Andrews J., Mulholland B.J., McKee J.M., Hilton H W., Horridge J.S., Farquhar G.D., Smeeton R.C., Smillie I.R., Black C.R., Taylor I.B., 2007. Overproduction of abscisic acid in tomato increases transpiration efficiency and root hydraulic conductivity and influences leaf expansion. Plant Physiol. 143:1905-1917.

Tilman D., Fargione J., Wolff B., D'Antonio C., Dobson A., Howarth R., Schindler D., Schlesinger W.H., Simberloff D., Swackhamer D.,Tilman, D. 2001. Forecasting agriculturally driven global environmental change. Science 292:28-284.

Tixier P., Bon H. de, 2006. Urban Horticulture. In: R. van Veenhuizen (ed.) Cities Farming for the Future, Urban Agriculture for Green and Productive Cities. RUAF Foundation, IDRC and IIRR, Silang, The Philippines. Available from: http://www.ruaf.org/node/961

UN, 2009. United Nations Population Information Network. Available from: www.un.org/popin/data.html

UN-DESA, 2007. World population prospects: the 2007 revision population database. Available from: http://esa.un.org/unup

Urao T., Yakubov B., Satoh R., Yamaguchi-Shinozaki K., Seki M., Hirayama T., Shinozaki K., 1999. A transmembrane hybrid-type histidine kinase in Arabidopsis functions as an osmosensor. Plant Cell 11:1743-1754.

van Veenhuizen R., 2006. Introduction Cities Farming for the Future. In: R. van Veenhuizen (ed.) Cities farming for the future, urban agriculture for green and productive cities. RUAF Foundation,
IDRC and IIRR, Silang, The Philippines. Available from: http://www.ruaf.org/node/961

Vavilov N.I., 1914. Immunity to fungous diseases as a physiological test in genetics and systematics, exemplified in cereals. J. Genetics 4:49-65.

Verslues P.E., Zhu J.K., 2007. New developments in abscisic acid perception and metabolism. Curr. Opin. Plant Biol. 10:447-452.

Vleeshouwers V.G.A.A., Rietman H., Krenek P., Champouret N., Young C., Oh, S.K., Wang M., Bouwmeester K., Vosman B., Visser R.G.F., Jacobsen E., Govers F., Kamoun S., Van der Vossen1 E.A.G., 2008. Effector genomics accelerates discovery and functional profiling of potato disease resistance and Phytophthora infestans avirulence genes. PLoS ONE 3:e2875.

Wong N., Cheong D., Yan H., Soh J., Ong C., Sia A., 2003. The effect of rooftop garden on energy consumption of a commercial building in Singapore. Energ. Buildings 35:353-364.

Xia T., Apse M.P., Aharon G.S., Blumwald E., 2002. Identification and characterization of a $\mathrm{NaCl}$-inducible vacuolar $\mathrm{Na}+\mathrm{H}+$ antiporter in Beta vulgaris. Physiol. Plant 116:206-212

Xiong L., Schumaker K.S., Zhu J.K. 2002. Cell signaling during cold, drought, and salt stress. Plant Cell 14:S165-S183.

Yu H, Chen X., Hong Y.Y., Wang Y., Xu P., Ke S.D., Liu H.Y., Zhu J.K., Oliver D.J., Xiang C.B., 2008. Activated expression of an Arabidopsis HD-START protein confers drought tolerance with improved root system and reduced stomatal density. Plant Cell 20:1134-1151.

Zhang H.X., Blumwald E., 2001. Transgenic salt-tolerant tomato plants accumulate salt in foliage but not in fruit. Nature Biotech. 19:765768.

Zhu J.K., 2002. Salt and drought stress signal transduction in plants. Annual Review of Plant Biology 53:247-273.

Zhu J.K., 2009. Active DNA demethylation mediated by DNA glycosylases. Annu. Rev. Genet. 43:143-66. 